\title{
Investigation of the awareness and effects of naturally changing compositional aspects in kombucha tea, due to natural fermentation processes
}

\author{
Carlson $\mathrm{Chao}^{1}$, Dale Chen ${ }^{2}$
}

1 Lead Author, Lead Author, B.Tech Student, School of Health Science, British Columbia Institute of Technology, 3700 Willingdon Ave, Burnaby BC, V5G3H2

2 Supervisor, School of Health Science, British Columbia Institute of Technology, 3700 Willingdon Ave, Burnaby BC, V5G3H2

\section{Abstract \\ $\underline{\text { Background }}$}

With the growing popularity of Kombucha, more people are beginning to either purchase or make their own Kombucha beverage. Due to the relatively recent rise in popularity, within the general public, not as much is known about the beverage compared to other beverages that have been on the market longer such as beer. This is important and relevant to public health because, due to the nature of the production method used to create Kombucha, the drink itself may contain alcohol. While at the time of production and distribution, the levels of alcohol are below the regulated maximum of $1 \%$, these levels may increase on their own if measures were not put in place to stop the beverage from self-fermenting post-distribution. Kombucha is sold as a non-alcoholic beverage as they aren't required to be defined as liquor (because it is $<1 \%$ ethanol), when in reality, they may contain more than $1 \%$ ethanol due to the self-fermentation process. This poses as a potential health risks to people who do not consume alcohol for personal reasons or to adolescents who should not be consuming alcohol.

\section{Methods}

This research involved the utilization of a self-administered online survey with the inclusion criteria of anyone in the general public, with exclusions of minors ( $<18$ years of age) from the data analysis. The survey was distributed through Reddit on subreddits such as r/takemysurvey, r/samplesize, r/BCIT, etc... The survey consisted of ten questions to gather demographic information, as well as assess the participant's knowledge level for various aspects regarding kombucha.

\section{$\underline{\text { Results }}$}

The reasons why participants consume Kombucha is heavily influenced by their knowledge of the ingredients within the beverage ( $p$-value of 0.0000 ). These further correlates to how frequently they consume it, how many reasons they have for consuming it, and their various age groups. Statistical analysis on the survey participant population resulted in the following significance values:

$>$ Ingredient awareness and consumption frequency: p-value of 0.0000

$>$ Age group and consumption frequency: $\mathrm{p}$-value of 0.0000

$>$ Consumption frequency and number of reasons for consumption: $\mathrm{p}$-value of 0.0000 
Education level and fermentation occurrence knowledge: p-value of 0.0444

$>$ Storage temperature knowledge and fermentation occurrence knowledge: $p$-value of 0.7344

The statistical significance threshold set for these analyses was 0.05 .

\section{$\underline{\text { Conclusions }}$}

With the results of this study, there is strong indication in the need for further public education regarding Kombucha's potential to ferment and that the storage temperature/environment of the kombucha is very important in preventing fermentation from occurring. Further regulations are needed to ensure that all manufacturing processes involve an inactivation step for the bacteria in Kombucha or requiring labelling on the cans/bottles themselves, indicating the need for refrigeration.

Key Words: kombucha, ethanol, fermentation, survey

\section{Introduction}

According to Google Trends (2020), kombucha has gained popularity in the last 10 or so years as seen in Figure 1.

Figure 1: Interest over time for the search term "kombucha" on Google Trends

₹ Worldwide, 2004 - present

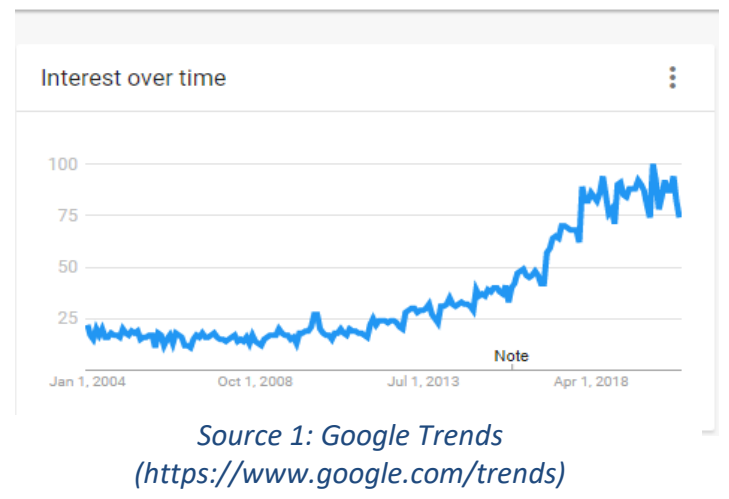

This could mean that more people are beginning to purchase and consume the beverage. However, because this is a product that has risen in popularity recently, not as much is known about it as other beverages that have been on the market for a longer period of time. The goal of this research project is to collect and analyze data on the knowledge level that people have for kombucha. This is important and relevant to public health because the beverage itself contains alcohol but at the time of production and distribution, the levels are not high enough to be impacted by alcohol regulations in British Columbia (BCCDC, 2015). The regulations state that a maximum of $1 \%$ ethanol is permitted in beverages before they are defined as liquor (Liquor Control and Licensing Act, 2015). This means kombucha is often sold as a non-alcoholic drink even though there is alcohol in it (BCCDC, 2015). Storing kombucha at room temperatures also sometimes allows continued fermentation of the drink to increase the alcohol content even further (Mayser et al., 1995), which may pose as a health risk to people who do not consume alcohol or adolescents.

\section{Literature Review}

\section{Health Hazards Associated with Kombucha}

While kombucha is deemed as a low-risk product because of its inherent characteristics of being highly acidic, consuming too much of the acidic beverage, 
may pose as a public health risk to susceptible populations (BCCDC, 2015). Examples of the susceptible populations according to the BCCDC (2015) are:

$>$ People practicing religion who abstain from alcohol consumption

$>$ People who are on prescription medication who cannot consume alcohol

$>$ People with substance use disorders who are trying to avoid alcohol (such as recovering alcoholics).

There have been research studies that were published studying the neurocognitive effects of alcohol on adolescents and college students which showed that there were correlations between the consumption of alcohol and elevated risks of neurodegeneration (Zeigler et al., 2005). It was observed that there was a risk in the neurodegeneration of the areas of the brain responsible for learning and memory as well as impairing brain activity. This is important to note because while the sale and distribution of alcohol to minors is against the law according to the Liquor Control and Licensing Act (2015), the continued fermentation of some kombucha products can elevate the ethanol content in an otherwise defined nonalcoholic beverage.

Adolescents and/or children face the risk of acquiring kombucha under the assumption that it is a nonalcoholic beverage, only to consume alcohol due to the continued natural fermentation of the yeast in the kombucha. This can negatively affect their development and can have life-long consequences for those individuals (Zeigler et al., 2005).

BCCDC (2015) mentions that there are two major hazards that may occur in the commercial production of kombucha which can pose as a health hazard to the public. As with any food product, there can be biological contamination to the product. In the case of kombucha production, microorganisms can contaminate the product between two critical steps of after boiling the tea and before fermentation begins (BCCDC, 2015). This is relevant because not following proper safety measures in the production of kombucha, may lead to adverse health effects. Furthermore, the alcohol content in kombucha also plays a crucial role in the safety of the beverage (only after the completion of the fermentation process) (BCCDC, 2015). Alcohol in and of itself is an antibacterial agent and as kombucha contains alcohol, inherently, it would also have antibacterial properties to a degree (BCCDC, 2015). This was demonstrated in an antibacterial activity test outlined by Velicanski et al., (2014), which showed that kombucha exhibited antibacterial activity. In a study conducted by NeffeSkocinska et al., (2017), it was observed that the ethanol content (amount of alcohol) for kombucha stored at $20^{\circ} \mathrm{C}$ (room temperature) increased by $11.0 \%$ after 10 days of fermentation.

In the study conducted by Skocinska et al., (2017), the ethanol content after $0,3,7$ and 10 days of fermentation was statistically analyzed using a twoway analysis of variance which resulted in a p-value of 0.06. This is greater than the statistical significance threshold of 0.05 , meaning the data was statistically insignificant. However, due to the closeness of the resultant $p$-value to the threshold of statistical significance, the ethanol content should still be taken into consideration. The increased levels of ethanol content after 10 days may pose as a health risk to individuals who consume kombucha under the 
impression that there is no alcohol contained in it. Methods of prevention from allowing the continued fermentation post-distribution will be discussed later in this literature review.

Similarly, pH plays an important role in the safety of food products. A study that was conducted in 2019 showed that the $\mathrm{pH}$ values of kombucha tea ranged from 2.70 to 2.94 after a 15-day fermentation period (Kaewkod, Bovonsombut, Tragoolpua, 2019) as shown in Figure 2.

Figure 2: The Change in $\mathrm{pH}$ for Kombucha Tea Over a 15 Day Period

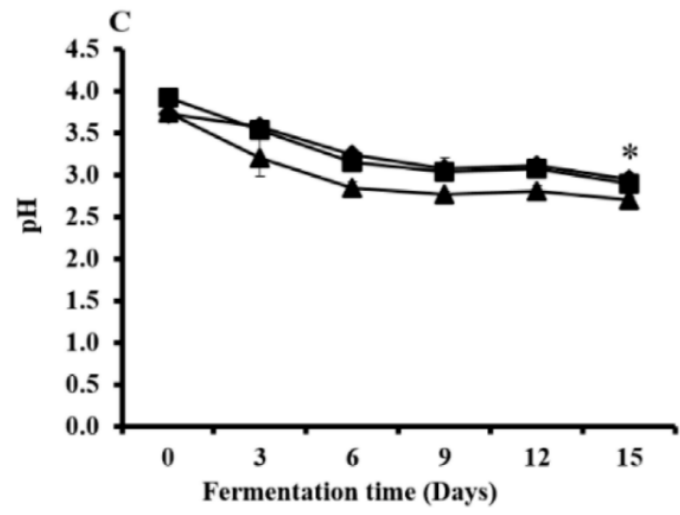

Source 2: Kaewkod, Bovonsombut, Tragoolpug (2019)

The low $\mathrm{pH}$ levels of kombucha tea indicates that spoilage of the beverage would be unlikely due to the $\mathrm{pH}$ being lower than 4.6 which is the threshold at which toxin-producing microorganisms are inhibited (Rushing, n.d.). A study conducted by Nummer (2013) indicated that if the $\mathrm{pH}$ of the beverage does not reach a $\mathrm{pH}$ level less than 4.2 within seven days, then the culture of bacteria used in the fermentation of the beverage is most likely to be contaminated or the fermentation temperature is too low for the fermentation process to take place.

Furthermore, in a case study conducted by the Center for Disease Control, a 59-year-old woman was found unconscious in her home which was later determined to have been caused by acidosis (increased acidity in the blood and other body tissues). This was caused by consuming highly acidic, overly fermented kombucha which can have the potential to cause perforations to occur in the intestinal tract within susceptible populations.

\section{$\underline{\text { Health Hazard Prevention }}$}

All this information helps build an understanding of the risks associated with kombucha. There are several factors that must be monitored and maintained in order to safely produce the beverage. The BCCDC (2015) outlines various methods to prevent potential hazards from arising at various processing steps. To combat the natural self-fermentation of kombucha tea post-distribution, it is recommended that the finished kombucha tea product is pasteurized to deactivate the fermentation producing bacteria. Preservatives can also be added into the kombucha tea to prevent the growth of mold and minimize yeast growth. Nummer (2013) mentions how SOPs (standard operating procedures) for kombucha production can be written to help accomplish food safety objectives. This plays a critical role in the maintenance and prevention of foodborne illnesses from emerging because if a detailed recipe and procedure were to be followed, deviation (mistakes) in the process would not occur as often, enabling the target of safe food to be reached easier. Furthermore, SOPs usually have documented actions that should be taken should a deviation occur. This would allow for a faster response to deviations allowing a rapid remedial process.

Many factors that cause health hazards from occurring due to the consumption of kombucha stem from the 
over-fermentation of the yeast in kombucha tea (Mayser, 1995). This is because due to overfermentation, the acetic acid production can lower the $\mathrm{pH}$ of the tea to below safe levels of consumption, causing acidosis to susceptible populations who consume the tea (BCCDC, 2015). Over-fermentation can also cause elevated levels of ethanol content in the tea which can cause neurodegeneration (Zeigler et al., 2005). Therefore, the $\mathrm{pH}$ and prevention of fermentation post-distribution must be closely monitored.

Kombucha is seen as a beverage that can be both purchased from the store as well as made/brewed in a home setting. Therefore, due to home-brewing not being regulated, education in the requirements of safe production must be presented in an easily accessible manner. As kombucha is a relatively new, popular beverage, specifics as to the requirements of kombucha tea composition and processing methods are not yet well established which is seen in the varying ethanol content and self-fermentation of some kombucha tea products (Jayabalan et al., 2014).

\section{Health Benefits Associated with the}

\section{Consumption of Kombucha Tea}

Although there are risks associated with kombucha tea, there are also benefits associated with the beverage. A study conducted by Kapp \& Sumner (2018) demonstrated that the health benefits of kombucha tea derive from the tea itself as well as the products of fermentation. Some examples of these fermentation products stated by Kapp \& Sumner (2018) include:

$>$ Polyphenols

$>$ Glucuronic acid

$>$ Acetic acid,
$>$ B-complex vitamins

$>$ Phenols.

Furthermore, it was also observed that kombucha tea exhibited several other effects such as immune system stimulation, antimicrobial aspects which can benefit the body, and improvement in liver \& gastrointestinal functions (Kapp \& Sumner, 2018). This is further supported through the study conducted by Jayabalan et al., (2014) which mentions how there is an antioxidant property in kombucha tea "due to the presence of polyphenols, ascorbic acid, and DSL [(Dsaccharic acid-1,4-lactone)]".

According to Nazario, B. (2020), the base ingredient of green tea and the fermentation process, creates the presence of antioxidants as well as probiotics. This fermentation process is performed through a colony of different yeasts and bacteria which are commonly referenced as a Symbiotic Culture of Bacteria and Yeasts (or SCOBY) (Villarreal-Soto et al., 2018).

\section{Literature Review Conclusion}

Literature review had revealed that there are several things that affect the safety in production of kombucha and that not meeting those critical steps may lead to adverse health effects in susceptible populations. Conversely, there are also many benefits to the consumption of kombucha such as its antioxidant properties, immune stimulation, gastrointestinal functions, etc... Finally, the 2 major components of focus should be centered around monitoring and controlling ethanol content and $\mathrm{pH}$ during production as well as post-distribution.

The goal of this research is to gather survey data in the knowledge level of people regarding kombucha tea and to assess whether people are aware of the potential 
for yeast to alter the composition of kombucha tea post-production. Introduction of different legislation and labelling practices over kombucha tea products would help aid in the transition to allowing consumers to make a more informed purchase. This would involve manufacturers and distributors such as retailers to implement more detailed labelling and signage which warns the public about the possible alcohol content that is present in the kombucha tea. This will help to ensure the beverage is produced and distributed in a safe manner to a more well-informed public.

\section{Methodology}

\section{Materials Used in Study}

This research involved the utilization of a selfadministered online survey through the Survey Monkey platform (http://www.surveymonkey.com/) with the inclusion criteria of anyone in the general public, with exclusions of minors ( $<18$ years of age) from the data analysis. Descriptive statistics was performed on the data collected in the form of tables and bar charts (with counts and percentages) and inferential statistics through the chi-squared test using NCSS (2021).

\section{$\underline{\text { Inclusion and Exclusion Criteria }}$}

The people that were included in the data analysis for the survey data was people in the general public (with no geographic restriction) who consume or know about kombucha tea that are 18 years of age or greater at the time of survey completion. This is because the premise of this research paper is to assess the level of knowledge and awareness for the factors associated with kombucha tea of as many people as possible. People who are excluded in the data analysis for the survey will be those who do not know what kombucha is as well as youth under the age of 18 .

For those who do know what kombucha tea is, the information collected will help gauge if the potential health hazards and ramifications of consumption are well known in the general population.

\section{Ethical Considerations}

There are certainly ethical considerations for the questions that are being asked in the survey. For example, one of the survey questions that was posed is one where it is trying to identify the age group that the participant is in. This acts as an indicator of the participant which can potentially absolve their anonymity if links were to be made. This principle can be applied to several questions in the survey which is why anonymity was so important in this sense.

All information that is collected in this research was kept confidential. The online survey is hosted and run by SurveyMonkey and their applicable end-user agreements and security measures. Any data that was downloaded for analysis was kept in the principal investigator's computer and the files was all password protected. Participants had the option to leave their email address to enter into a prize draw. Doing this made their responses not anonymous however, this was a non-compulsory question and participants may opt out of the prize draw, thus allowing them to remain anonymous.

This research project has been reviewed and approved by the BCIT Research Ethics Board which ensures that the research complies with BCIT's Research Ethics guidelines. 


\section{Results}

\section{$\underline{\text { Descriptive Statistics }}$}

The data that was collected from the completion of the survey included non-numerical ordinal data as well as non-numerical nominal/categorical data. Descriptive statistics were provided in the survey results page of the survey from SurveyMonkey (examples shown in Table 1 and Figure 3). The data was displayed in tables and bar charts with counts and percentages. No numerical data was collected therefore means, modes, medians, and ranges are not applicable.

Table 1: Descriptive Statistics Table for the Survey Question: Which age group are you in?

\begin{tabular}{llr} 
ANSWER CHOICES & RESPONSES & - \\
\hline Under 18 & $9.39 \%$ & 20 \\
\hline 18-24 & $53.05 \%$ & 113 \\
\hline 25-39 & $32.86 \%$ & 70 \\
\hline$\quad 40-60$ & $3.76 \%$ & 8 \\
\hline Greater than 60 & $0.00 \%$ & 0 \\
\hline I prefer not to answer & $0.94 \%$ & 2 \\
\hline TOTAL & & 213 \\
\hline
\end{tabular}

Figure 3: Descriptive Statistics Bar Chart for the Survey Question: Which age group are you in?

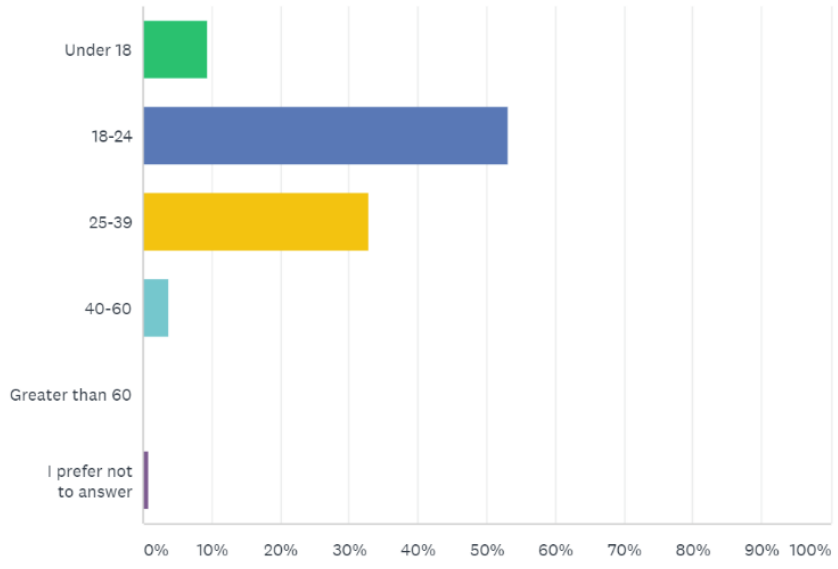

\section{$\underline{\text { Inferential Statistics }}$}

The chi-squared test was performed between various questions to compare the frequencies/proportions between two groups. This is because some of the data is non-numerical ordinal data (example: knowledge level) and some is non-numerical nominal data (example: country of residence). Inferential statistics will be performed on:

$>$ Association between people knowing ingredients in kombucha and how frequently they consume kombucha

$>$ Association between age group and how frequently they consume kombucha

Association between frequency of consumption and why people consume it

$>$ Association between education level and knowledge of when fermentation occurs in kombucha production

$>$ Association between people's knowledge of storage temperatures for kombucha and their knowledge of when fermentation occurs in kombucha production

The statistical package that was used to analyze the data was NCSS 2021 Statistical Analysis Package. 


\section{Chi-Square Test Results}

Table 2: Statistical Analysis Summary and Conclusions

\begin{tabular}{|c|c|c|c|}
\hline $\mathrm{H}_{0}$ and $\mathrm{H}_{\mathrm{A}}$ & Test Used & $\begin{array}{l}\text { Result } \\
\text { (p-value) }\end{array}$ & Conclusion \\
\hline $\begin{array}{l}\text { Ingredient Awareness and } \\
\text { Consumption Frequency } \\
\mathbf{H}_{0}: \text { There is no statistically } \\
\text { significant association between } \\
\text { the awareness people have for } \\
\text { the ingredients in kombucha and } \\
\text { how frequently they consume } \\
\text { kombucha. }\end{array}$ & Chi-square test & 0.0000 & $\begin{array}{l}\text { p-value }=0.0000 \text {, therefore we can } \\
\text { reject the } \mathrm{H}_{0} \text { and conclude that there is } \\
\text { a statistically significant association } \\
\text { between people's knowledge of } \\
\text { ingredients in kombucha and how } \\
\text { frequently they consume kombucha. It } \\
\text { would appear that people who } \\
\text { consume kombucha are aware of its } \\
\text { ingredients. }\end{array}$ \\
\hline $\begin{array}{l}\mathbf{H}_{\mathrm{A}} \text { : There is a statistically } \\
\text { significant association between } \\
\text { the awareness people have for } \\
\text { the ingredients in kombucha and } \\
\text { how frequently they consume } \\
\text { kombucha. }\end{array}$ & & & $\begin{array}{l}\text { The power for this analysis is } \\
\text { estimated to be relatively high as all of } \\
\text { the categories exceed } 30 \text { total } \\
\text { responses with the exception of "I am } \\
\text { very aware" and "Daily/a few times a } \\
\text { week" with } 28 \text { and } 26 \text { responses } \\
\text { respectively. Estimation was required } \\
\text { as power was not calculated. More } \\
\text { responses in these categories would } \\
\text { increase the power of this analysis. }\end{array}$ \\
\hline $\begin{array}{l}\text { Age Group and Consumption } \\
\text { Frequency } \\
\mathbf{H}_{\mathbf{0}} \text { : There is no statistically } \\
\text { significant association between } \\
\text { the different age groups and how } \\
\text { frequently they consume } \\
\text { kombucha. }\end{array}$ & Chi-square test & 0.0000 & $\begin{array}{l}\mathrm{p} \text {-value }=0.0000 \text {, therefore we can } \\
\text { reject the } \mathrm{H}_{0} \text { and conclude that there is } \\
\text { a statistically significant association } \\
\text { between people's age group and how } \\
\text { frequently they consume kombucha. It } \\
\text { would appear that people's age affects } \\
\text { how often they consume kombucha. }\end{array}$ \\
\hline $\begin{array}{l}\mathbf{H}_{\mathrm{A}} \text { : There is a statistically } \\
\text { significant association between } \\
\text { the different age groups and how } \\
\text { frequently they consume } \\
\text { kombucha. }\end{array}$ & & & $\begin{array}{l}\text { The power for this analysis is } \\
\text { estimated to be relatively high as all of } \\
\text { the categories exceed } 30 \text { total } \\
\text { responses with the exception of } \\
\text { "Greater than } 40 \text { " and "Daily/a few } \\
\text { times a week" with } 8 \text { and } 26 \text { responses } \\
\text { respectively. Estimation was required } \\
\text { as power was not calculated. More }\end{array}$ \\
\hline
\end{tabular}




\begin{tabular}{|c|c|c|c|}
\hline & & & $\begin{array}{l}\text { responses in these categories would } \\
\text { increase the power of this analysis. }\end{array}$ \\
\hline $\begin{array}{l}\text { Consumption Frequency and } \\
\text { Number of Reasons for } \\
\text { Consumption } \\
\mathbf{H}_{0} \text { : There is no statistically } \\
\text { significant association between } \\
\text { the frequency of consumption } \\
\text { and the reason why people } \\
\text { consume kombucha. }\end{array}$ & Chi-square test & 0.0000 & $\begin{array}{l}\text { p-value }=0.0000 \text {, therefore we can } \\
\text { reject the } \mathrm{H}_{0} \text { and conclude that there is } \\
\text { a statistically significant association } \\
\text { between kombucha consumption } \\
\text { frequency and the reason behind why } \\
\text { people consume kombucha. It would } \\
\text { appear that the frequency of } \\
\text { consumption for kombucha is affected } \\
\text { by how many reasons people have for } \\
\text { consuming kombucha. }\end{array}$ \\
\hline $\begin{array}{l}\mathbf{H}_{\mathrm{A}} \text { : There is a statistically } \\
\text { significant association between } \\
\text { the frequency of consumption } \\
\text { and the reason why people } \\
\text { consume kombucha. }\end{array}$ & & & $\begin{array}{l}\text { The power for this analysis is } \\
\text { estimated to be relatively low as } 3 / 8 \\
\text { categories have less than } 30 \text { responses, } \\
\text { including: } 3,4 \text {, and } 5 \text { number of } \\
\text { consumption reasons. Estimation was } \\
\text { required as power was not calculated. } \\
\text { More responses in these categories } \\
\text { would increase the power of this } \\
\text { analysis. }\end{array}$ \\
\hline $\begin{array}{l}\text { Education Level and } \\
\text { Fermentation Occurrence } \\
\text { Knowledge } \\
\mathbf{H}_{0} \text { : There is no statistically } \\
\text { significant association between } \\
\text { people's education level and the } \\
\text { level of knowledge they have of } \\
\text { when fermentation occurs in } \\
\text { kombucha production. }\end{array}$ & Chi-square test & 0.0444 & $\begin{array}{l}\mathrm{p} \text {-value }=0.0444 \text {, therefore we can } \\
\text { reject the } \mathrm{H}_{0} \text { and conclude that there is } \\
\text { a statistically significant association } \\
\text { between people's education level and } \\
\text { their knowledge of when fermentation } \\
\text { occurs in the production of kombucha. } \\
\text { It would appear that people's } \\
\text { education levels affects how much } \\
\text { they know about when fermentation } \\
\text { occurs for the production of } \\
\text { kombucha. }\end{array}$ \\
\hline $\begin{array}{l}\mathbf{H}_{\mathrm{A}} \text { : There is a statistically } \\
\text { significant association between } \\
\text { people's education level and the } \\
\text { level of knowledge people have } \\
\text { of when fermentation occurs in } \\
\text { kombucha production. }\end{array}$ & & & $\begin{array}{l}\text { The power for this analysis is } \\
\text { estimated to be relatively high as all of } \\
\text { the categories exceed } 30 \text { total } \\
\text { responses with the exception of "More } \\
\text { than Bachelor's Degree" and "After } \\
\text { production" with } 12 \text { and } 13 \text { responses } \\
\text { respectively. Estimation was required } \\
\text { as power was not calculated. More }\end{array}$ \\
\hline
\end{tabular}




\begin{tabular}{|c|c|c|c|}
\hline & & & $\begin{array}{l}\text { responses in these categories would } \\
\text { increase the power of this analysis. } \\
\text { Potential alpha error could have } \\
\text { occurred in this analysis as } 0.0444 \text { is } \\
\text { very close to the cut-off of } 0.05 \text {. } \\
\text { Reducing the p-value cutoff to } 0.01 \\
\text { would minimize this alpha error which } \\
\text { would increase the overall power of } \\
\text { the statistical analysis. This was not } \\
\text { done in this analysis as to stay } \\
\text { consistent with the other analyses } \\
\text { performed. }\end{array}$ \\
\hline $\begin{array}{l}\text { Storage Temperature Knowledge } \\
\text { and Fermentation Occurrence } \\
\text { Knowledge } \\
\mathbf{H}_{\mathbf{0}} \text { : There is no statistically } \\
\text { significant association between } \\
\text { the public's knowledge of } \\
\text { storage temperatures for } \\
\text { kombucha and their } \\
\text { understanding of when } \\
\text { fermentation occurs in } \\
\text { kombucha production. } \\
\\
\mathbf{H}_{\mathrm{A}} \text { : There is a statistically } \\
\text { significant association between } \\
\text { people's knowledge of storage } \\
\text { temperatures for kombucha and } \\
\text { their knowledge level of when } \\
\text { fermentation occurs in } \\
\text { kombucha production. }\end{array}$ & Chi-square test & 0.7344 & $\begin{array}{l}\text { p-value }=0.7344 \text {, therefore we do not } \\
\text { reject the } \mathrm{H}_{0} \text { and conclude that there is } \\
\text { no statistically significant association } \\
\text { between people's knowledge of proper } \\
\text { storage temperature for kombucha and } \\
\text { their knowledge of when fermentation } \\
\text { occurs in the production of kombucha. } \\
\text { The power for this analysis is } \\
\text { estimated to be relatively high as all of } \\
\text { the categories exceed } 30 \text { total } \\
\text { responses with the exception of "After } \\
\text { production" which had } 13 \text { responses. } \\
\text { Estimation was required as power was } \\
\text { not calculated. More responses in this } \\
\text { category would increase the power of } \\
\text { this analysis. }\end{array}$ \\
\hline
\end{tabular}




\section{Discussion}

\section{$\underline{\text { Study Findings }}$}

Based on the results that were collected and analyzed, the most common reason behind why the participants consume Kombucha were because of the ingredients inside Kombucha which provides health benefits (Kapp \& Sumner, 2018). This suggests that people may be purchasing kombucha for its ingredients and thinking that it has no alcohol (or has low alcohol) when there is still the possibility of increased alcohol levels because of fermentation. This also correlates to how frequently they consume it, how many reasons they have for consuming it, and their various age groups. Beneficial substances within Kombucha that Kapp \& Sumner (2018) outlined included polyphenols, glucuronic acid, acetic acid, B-complex vitamins, and phenols which were perhaps what people were looking for when consuming kombucha.

The data also showed that there was no association between people's knowledge of proper storage temperatures for kombucha and when fermentation occurs for kombucha. This would indicate that people do not generally know of possibility that kombucha has a chance to self-ferment post-production which may produce excess levels of alcohol and increased acidity in the beverage. This is important to note because as mentioned in the literature review, BCCDC (2015) mentioned how consuming too much of an acidic beverage or consuming too much alcohol in general could pose as a health risk to susceptible individuals. Those who may be unable to consume alcoholic beverages because they are, practicing religion who abstain from alcohol consumption, people who are on prescription, or they are people with substance use disorders who are trying to avoid alcohol.

With health hazard prevention in mind, the results that were gathered in this research studied showed that the general public does not necessarily know or understand the association between fermentation and storage temperatures. This would indicate that they may unknowingly store the kombucha beverage at room temperature, and if the fermentation producing bacteria in the particular kombucha beverage was not inactivated before distribution, then there lies the possibility of further fermentation which could increase the acidity level, as well as the alcohol content. This may ultimately pose a risk to people which were described earlier. This means that the findings generally agree with previous research in the importance of preventing fermentation from occurring post-production as stated in other literature (BCCDC, 2015).

\section{Limitations}

The most prevalent limitation is that there were not enough participants in the survey which cause some of the categories to be below 30 participants. This forced the combining of different categories during the data analysis process to reach as high as possible answers per category. These actions could have been avoided if there were more participants in the survey. In order to have more participants in the study, a longer survey response period could have been employed, or more advertisement in different places. Furthermore, increasing sample size and age group representation could be improved through reaching out to the general public in different manners other than through the online platform Reddit. Examples of 
new areas for distribution could include door-to-door canvasing, setting up a table in a popular area to invite survey participants, and calling people to ask for responses. However, these also have limitations, the most prominent being the resource requirements for performing these types of survey distribution methods as all of these would be much more intensive.

Another limitation that occurred for this research was due to the nature of a self-administered online survey is survey fraud (Howard, 2019). This is when the respondent does not answer questions truthfully either intentionally or unintentionally. This could be caused due a variety of reasons such as, speeding through the survey answering the questions randomly to reach the reward at the end. Or, if the question was worded in a confusing manner or in a way that doesn't make sense to the respondent, then they tend to pick a random answer rather than leave the question blank. This could have caused inaccurate survey results that don't represent what the survey participants actually think of the questions. There aren't any viable solutions to preventing this from occurring in this particular research other than trusting that the participants complete the questions in an honest and accurate manner.

Moreover, limitations in age group representation have also occurred. This is because of the means for distribution that this survey had. The distribution method for this self-administered online survey was through the online platform Reddit. And as more young people typically use this site compared to the older generation, there would not be a representative population for the older age groups such as the greater than 40 age group.
Another limitation in the study was due to the lack of an interviewer. This could have affected people in the way that they aren't able to ask for clarifications for questions which could lead to unreliable data (Howard, 2019).

\section{$\underline{\text { Knowledge Translation and Recommendations }}$} Introduction of different legislation and labelling practices over kombucha tea products would help aid in the transition to allowing consumers to make a more informed purchase. This would involve manufacturers and distributors such as retailers to implement more detailed labelling and signage which warns the public about the possible alcohol content that is present in the kombucha tea. Legislation would ensure that all kombucha processors that plan to sell commercially, abide by labelling or manufacturing standards which disables fermentation postproduction. This is important in maintaining the $<1 \%$ ethanol threshold for being defined as an alcoholic beverage.

Implementation of other ideas could include the potential future requirements for preventative measures in the manufacturing process for Kombucha tea. Examples of this can be pasteurization or the addition of additives to inactivate fermenting bacteria, or other labelling practices which could include phrases on packaging and bottles such as "keep under refrigeration" or "this product must be refrigerated".

This will all hopefully help to ensure kombucha is produced and distributed in a safe manner to a more well-informed public. 


\section{$\underline{\text { Future Research }}$}

The following are some potential research project ideas:

Laboratory analysis on the actual properties that change throughout the shelf-life of commercial Kombucha tea (such as ethanol content, $\mathrm{pH}, \mathrm{a}_{\mathrm{w}}$, etc...)

$>$ Nutritional content analysis on different commercial Kombucha tea products

$>$ Investigation into the efficacy of preventative measures for stopping post-production fermentation from occurring

$>$ Repeating this study after legislative changes in manufacturing processes or labelling requirements are implemented.

\section{Conclusions}

From this research project, it was found that the general population does not know of or understand the importance of storage temperature when it comes to kombucha tea. This is significant in the sense that if fermentation producing bacteria is not inactivated in the commercial manufacturing process, then fermentation could occur post-production, leading to increased acidity, and ethanol content in the beverage. Some people purchase and consume kombucha under the assumption that it is not an alcoholic beverage and if unknown fermentation were to occur in the beverage, they may unknowingly consume the alcohol which may cause detrimental health effects to certain individuals.

This shows the importance in education of the public in regard to knowing that kombucha has the potential to ferment itself and that the storage temperature/environment of the kombucha is very important in preventing fermentation from occurring. This also demonstrates the discrepancy in manufacturing processes where some manufacturers have methods of inactivating fermentation producing bacteria whereas some do not. This shines the line on the need for regulation in ensuring that all manufacturing processes involve an inactivation step for the bacteria or requiring labelling on the cans/bottles themselves, indicating the need for refrigeration.

\section{Acknowledgements}

I would like to thank Lorraine McIntyre from the BCCDC for providing me with the opportunity to investigate this topic and report upon the findings. I would also like to thank my supervisor Dale Chen and instructor Helen Heacock for their support and insight throughout this project.

\section{Competing Interests}

The lead author declares that they have no competing interests in this study.

\section{References}

BCCDC. (2015, January 27). Food Safety Assessment of Kombucha Tea Recipe and Food Safety Plan. Retrieved from http://www.bccdc.ca/resourcegallery/Documents/Educational Materials/EH/FPS/Food/kombucha1.pdf

Bradbury, N. A. (2016). Attention span during lectures: 8 seconds, 10 minutes, or 
more? Advances in Physiology Education, 40(4), 509-513. doi:10.1152/advan.00109.2016

Data source: Google Trends (https://www.google.com/trends)

Finlay, S. C. (2014). Age and Gender in Reddit Commenting and Success. Journal of Information Science Theory and Practice, 2(3), 18-28. doi:10.1633/jistap.2014.2.3.2

Frost, J., \& Kuhlmann, D. (2020, May 30). Types of Errors in Hypothesis Testing. Retrieved November 20, 2020, from https://statisticsbyjim.com/hypothesistesting/types-errors-hypothesis-testing/

Glasow, P. A. (n.d.). Fundamentals of Survey Research Methodology. Mitre Product. Retrieved November 20, 2020, from https://www.mitre.org/sites/default/files/pdf/05 0638.pdf.

Google. (2020). Interest in Kombucha from 2004 to Present (2020). Retrieved October 15, 2020 , from

$\underline{\text { https://trends.google.com/trends/explore?date }=\mathrm{al}}$ $\underline{1 \& g e o=U S \& q=\text { kombucha }}$

Guidelines: Research Involving Minor Age Participants. (2020, July 29). Retrieved November 20, 2020, from https://www.yorku.ca/research/guidelines$\underline{\text { research-involving-minor-age-participants }}$

Howard, C. (2019, August 27). Advantages and Disadvantages of Online Surveys. Retrieved March 21, 2021, from https://www.cvent.com/en/blog/events/advantag es-disadvantages-online-surveys

Jayabalan, R., Malbaša, R. V., Lončar, E. S., Vitas, J. S., \& Sathishkumar, M. (2014). A Review on Kombucha Tea-Microbiology, Composition, Fermentation, Beneficial Effects, Toxicity, and Tea Fungus. Comprehensive Reviews in Food Science and Food Safety, 13(4), 538-550. doi:10.1111/1541-4337.12073

Kaewkod, T., Bovonsombut, S., \& Tragoolpua, Y. (2019). Efficacy of Kombucha Obtained from Green, Oolong, and Black Teas on Inhibition of Pathogenic Bacteria, Antioxidation, and Toxicity on Colorectal Cancer Cell

Line. Microorganisms, 7(12), 700.

doi:10.3390/microorganisms 7120700

Kapp, J. M., \& Sumner, W. (2019). Kombucha: A systematic review of the empirical evidence of human health benefit. Annals of Epidemiology, 30, 66-70.

doi:10.1016/j.annepidem.2018.11.001

Liquor Control and Licensing Act. (2015). Retrieved from

https://www.bclaws.ca/civix/document/id/compl ete/statreg/15019

Mayser, P., Fromme, S., Leitzmann, G., \& Gründer, K. (1995). The yeast spectrum of the 'tea fungus Kombucha'. Mycoses, 38(7-8), 289-295. doi:10.1111/j.1439-0507.1995.tb00410.x

McHugh, M. L. (2013). The Chi-square Test of Independence. Biochemia Medica. doi:10.11613/BM.2013.018 
Nazario, B. (2020, Aug 14 $\left.4^{\text {th }}\right)$ Kombucha. WebMD. Retrieved from:

https://www.webmd.com/diet/the-truth-aboutkombucha\#1

NCSS 2021 Statistical Software (2021). NCSS, LLC. Kaysville, Utah, USA, ncss.com/software/ncss.

Neffe-Skocińska, K., Sionek, B., Ścibisz, I., \& Kołożyn-Krajewska, D. (2017). Acid contents and the effect of fermentation condition of Kombucha tea beverages on physicochemical, microbiological and sensory properties. $C y T A$ Journal of Food, 15(4), 601-607. doi:10.1080/19476337.2017.1321588

Nummer, B. A. (2013). Kombucha Brewing Under the Food and Drug Administration Model Food Code: Risk Analysis and Processing Guidance. Retail-Foodservice Food Safety Consortium, 1-11. Retrieved October 15, 2020 , from http://food-safety.guru/wpcontent/uploads/2014/06/JEH1113 SSpecial_Report_Kombucha-Brewing.pdf

Rushing, J. E., Ph.D. (n.d.). Formulating Dressings, Sauces, and Marinades. North Carolina State University Department of Food Science, 1-4. Retrieved October 15, 2020, from https://fbns.ncsu.edu//extension_program/docum ents/acidified formulating_dressings.pdf.

Standards and Guidelines for Statistical Surveys. (2006). Substance Abuse and Mental Health Services (SAMHSA). Retrieved November 20, 2020, from https://www.samhsa.gov/data/sites/default/files/s tandards_stat_surveys.pdf
The Role of Probability. (n.d.). Retrieved from https://sphweb.bumc.bu.edu/otlt/mphmodules/bs/bs704_probability/BS704_Probabilit y12.html

Velicanski, A. S., Cvetkovic, D. D., Markov, S. L., Tumbas Saponjac, V. T., \& Vulic, J. J. (2014). Antioxidant and Antibacterial Activity of the Beverage Obtained by Fermentation of Sweetened Lemon Balm (Melissa officinalis L.) Tea with Symbiotic Consortium of Bacteria and Yeasts. Food Technol Biotechnol. doi:10.17113/ftb.52.04.14.3611

Villarreal-Soto, S. A., Beaufort, S., Bouajila, J., Souchard, J. P., \& Taillandier, P. (2018). Understanding Kombucha Tea Fermentation: A Review. Journal of food science, 83(3), 580588. https://doi.org/10.1111/1750-3841.14068

William C. Shiel Jr., M. (2018, December 04). Definition of Alpha error. Retrieved November 20, 2020, from https://www.medicinenet.com/alpha_error/defini $\underline{\text { tion.htm }}$

William C. Shiel Jr., M. (2018, December 04). Definition of Beta error. Retrieved November 20, 2020, from https://www.medicinenet.com/beta_error/definiti on.htm

Wood, E., Nosko, A., Desmarais, S., Ross, C., \& Irvine, C. (n.d.). Online and traditional paperand-pencil survey administration: Examining experimenter presence, sensitive material and long surveys. The Canadian Journal of Human Sexuality. Retrieved November 20, 2020, from 
https://search.proquest.com/openview/18590205

5d61b982c730e 5c0157db5d1/1?pq-

origsite $=$ gscholar $\& \mathrm{cbl}=33400$

Zeigler, D. W., Wang, C. C., Yoast, R. A.,

Dickinson, B. D., Mccaffree, M. A., Robinowitz,

C. B., \& Sterling, M. L. (2005). The

neurocognitive effects of alcohol on adolescents

and college students. Preventive

Medicine, 40(1), 23-32.

doi:10.1016/j.ypmed.2004.04.044 